\title{
Erratum to: Myocardial MIBG scintigraphy: \\ a useful clinical tool?
}

\section{A retrospective study in $\mathbf{5 0}$ parkinsonian patients}

\section{Ines Fröhlich • Wilfried Pilloy • Michel Vaillant •}

Nico J. Diederich

Published online: 14 April 2010

(C) Springer-Verlag 2010

\section{Erratum to: Neurol Sci}

DOI 10.1007/s10072-010-0218-4

Unfortunately, the order of the authors had been given incorrectly in our article. The order should be

Ines Fröhlich · Wilfried Pilloy · Michel Vaillant · Nico J. Diederich

The online version of the original article can be found under doi:10.1007/s10072-010-0218-4.

I. Fröhlich ( $\square)$

Centre Hospitalier Universitaire Vaudois (CHUV),

46 Rue de Bougnon, 1011 Lausanne, Switzerland

e-mail: ines.frohlich@chuv.ch; ines.froehlich@gmx.net

W. Pilloy · N. J. Diederich

Department of Neurology and Nuclear Medicine,

Centre Hospitalier de Luxembourg,

Luxembourg, Luxembourg

M. Vaillant

CRP Santé, Centre d'Etudes en Sante (CES),

Luxembourg, Luxembourg 